\title{
Chromosomal differentiation in Helianthus annuus var. macrocarpus: heterochromatin characterization and rDNA location
}

\author{
TERESA CUELLAR, ERIC BELHASSEN†, BEGOÑA FERNÁNDEZ-CALVÍN \\ JUAN ORELLANA $\$$ \& JOSE L. BELLA* \\ Departamento de Biología, Unidad de Genética, Facultad de Ciencias, Universidad Autónoma de Madrid, \\ E-28049 Madrid, Spain, †Génétique et Amélioration des Plantes, INRA, Place Pierre Viala 2, \\ F-34060 Montpellier, France and $\ddagger$ Departamento de Biotecnología, ETS/ Agrónomos, Universidad Politécnica de \\ Madrid, E-28040 Madrid, Spain
}

\begin{abstract}
The $2 n=34$ chromosomes of the inbred line HA89, and the Flamme and Mirasol hybrids of Helianthus annuus var. macrocarpus possess centromeric heterochromatin as established by Giemsa C-banding. This heterochromatin can not be differentiated by fluorochromes such as DAPI or Chromomycin A3, with selective affinity for specific DNA base pairs. This situation probably results from either a balanced AT/GC composition of the involved repeat or the existence of alternating repetitive sequences of opposite base pair composition in these heterochromatic areas. However, there is also heterochromatin associated with the secondary constrictions on three pairs of chromosomes. This heterochromatin appears to be GC-rich according to its response to the fluorochrome treatments, thus indicating heterochromatin heterogeneity in $H$. annuus. Silver staining reveals the existence of active NORs associated with these secondary constrictions. In situ hybridization with an rDNA probe confirms these results and makes the existence of other inactive rDNA sites unlikely. These results are relevant to evolutionary and breeding studies on sunflowers.
\end{abstract}

Keywords: chromosome banding, FISH, heterochromatin, NORs, sunflower cytogenetics.

\section{Introduction}

Although the genus Helianthus is of clear economic and evolutionary interest, the karyotypic status of the 50 or so species that make up the genus (Schilling \& Heiser, 1981) has not been analysed to any great extent (Chandler, 1991). Sunflower chromosomes have not been individually identified and numbered, so there are no cytological markers and no work on chromosome banding has been reported. Although some genetic linkage groups have been identified, they have yet to be localized to specific chromosomes (Rieseberg et al., 1993; Gentzbittel et al., 1995). Most of the karyological information about this taxon has come from the analysis of meiotic pairing in interspecific hybrids in the study of hybrid fertility, introgression and genome relationships (Chandler et al., 1986; Chandler, 1991). Our limited knowledge is a consequence of the

*Correspondence. intrinsic difficulties of studying an organism which has a relatively large number of comparatively small chromosomes. Furthermore, their occurrence in an oily cytoplasm makes good quality preparations difficult to obtain.

On the other hand, the use of banding techniques is a general procedure by which markers for individual chromosomes may be obtained, thereby permitting discrimination of species and varieties at the karyological level. In the sunflower the lack of such markers has made it difficult to analyse the introgression of economically interesting traits and the evolutionary relationships of the genus are not well understood. In fact, it has even been proposed that the recognized species of Helianthus are ecotypes of a single ecospecies (Kulshreshtha \& Gupta, 1979). As we show in this study, the use of pectinase treatment improves the quality of sunflower chromosomal preparations. This has allowed us to characterize the chromosomes of one of the commonest inbred lines and two varieties of the 
cultivated sunflower species Helianthus annuus $\mathrm{L}$. We describe the distribution of the constitutive heterochromatin, its response to specific DNA base pair ligands such as 4'-6-diamidino-2-phenylindole (DAPI) or Chromomycin A3, and the number and position of the Nucleolar Organizer Regions (NORs), as demonstrated by silver staining and fluorescence in situ hybridization (FISH) with an rDNA probe.

\section{Materials and methods}

Seeds from the inbred line HA89 of $H$. annuus var. macrocarpus and the commercial hybrids Mirasol and Flamme were grown in the dark at $25^{\circ} \mathrm{C}$. To obtain mitotic chromosomes arrested at metaphase, roots were collected after 3 days and placed in a 0.04 per cent solution of colchicine for $90 \mathrm{~min}$, fixed in 3:1 absolute ethanol:glacial acetic acid and stored at $4^{\circ} \mathrm{C}$. Roots were pretreated with a 0.5 per cent pectinase solution in standard $\mathrm{pH} 4.2$ citrate buffer for $1 \mathrm{~h}$ at $37^{\circ} \mathrm{C}$. The meristems were squashed in 45 per cent glacial acetic acid on microscope slides using a coverslip, the coverslip was removed with a razor blade after immersion in liquid nitrogen and the slides were air dried. Additionally, some root tips were stained employing the standard Feulgen technique and squashed on slides, according to Darlington \& La Cour (1976, pp. 125-127). A minimum of 15 roots per line or variety was studied for each technique employed.

C-banding and silver staining treatments were carried out according to Schwarzacher et al. (1980) and Lacadena et al. (1984), respectively, with minor modifications. Air-dried slides were stained after a minimum of 3 days with 4'-6-diamidino-2-phenylindole (DAPI) or Chromomycin A3 (CMA3) and counterstained with Distamycin-A (DA) or Actinomycin-D (AD), as described by Schweizer (1976, 1980).

The $9 \mathrm{kbp} E c o$ RI rDNA fragment of wheat containing the $18 \mathrm{~S}, 5.8 \mathrm{~S}$ and $26 \mathrm{~S}$ rRNA coding regions (plus the spacers), obtained from the pTA71 clone (Gerlach \& Bedbrook, 1979) was nick translated with digoxigenin-11-dUTP and in situ hybridized using the method of Pendás et al. (1993). Hybridization sites were detected with antidigoxigenin antibody conjugated to fluorescein isothiocyanate (FISH). Some slides were counterstained with propidium iodide $\left(2.5 \mu \mathrm{g} \mathrm{mL} \mathrm{mL}^{-1}\right)$ and mounted in Vecta Shield antifade solution (Vector Laboratories).

Preparations were examined at $100 \times$ magnification under a microscope equipped with a $100 \mathrm{~W}$ epifluorescence system and the appropriate filters for the observation of DAPI- and CMA3-stained chromosomes, and a double filter for the simultaneous observation of fluorescein and propidium iodide in the in situ hybridized chromosomes. Light field photographs were taken with Kodak Imagelink HQ film and Kodak Plus-X film was used for fluorescence and in situ hybridization photographs.

\section{Results}

The techniques used revealed no chromosomal differences among the line HA89 and the two hybrids of $H$. annuus studied.

\section{Feulgen staining}

Helianthus annuus has $2 n=34$ chromosomes of similar size which, following Al-Allaf \& Godward (1979), can be grouped as four pairs of metacentric (M1-M4), eight pairs of submetacentric (SM5-SM12) and five pairs of subtelocentric (ST13-ST17) chromosomes (Fig. 1a). The similarity in size and morphology of the chromosomes within each group makes further differentiation difficult. However, in all the cases considered, two pairs of submetacentric (SM7 and SM10) and one pair of subtelocentric (ST13) chromosomes show secondary constrictions (Figs 1a,b) which allow them to be distinguished.

\section{C-banding}

All the chromosomes possess small amounts of centromeric constitutive heterochromatin, and the three pairs of chromosomes bearing secondary constrictions (satellite chromosomes) also have associated heterochromatin (Fig. 1b). Distal or interstitial C-heterochromatin has not been revealed in any member of the complement. Variation in size between different individuals of these heterochromatic regions has not been observed.

\section{Fluorochrome staining}

DA-DAPI staining shows no positive response, but instead the chromosomes stain uniformly (Fig. 2a). Similarly, AD-DAPI does not reveal any clear differentiation, although some centromeric regions yield a diffuse, slightly positive response, although this cannot be reproduced photographically. However, in both cases the heterochromatin associated with the secondary constrictions appears negative, in contrast with the positive response it shows with DA-CMA3. 

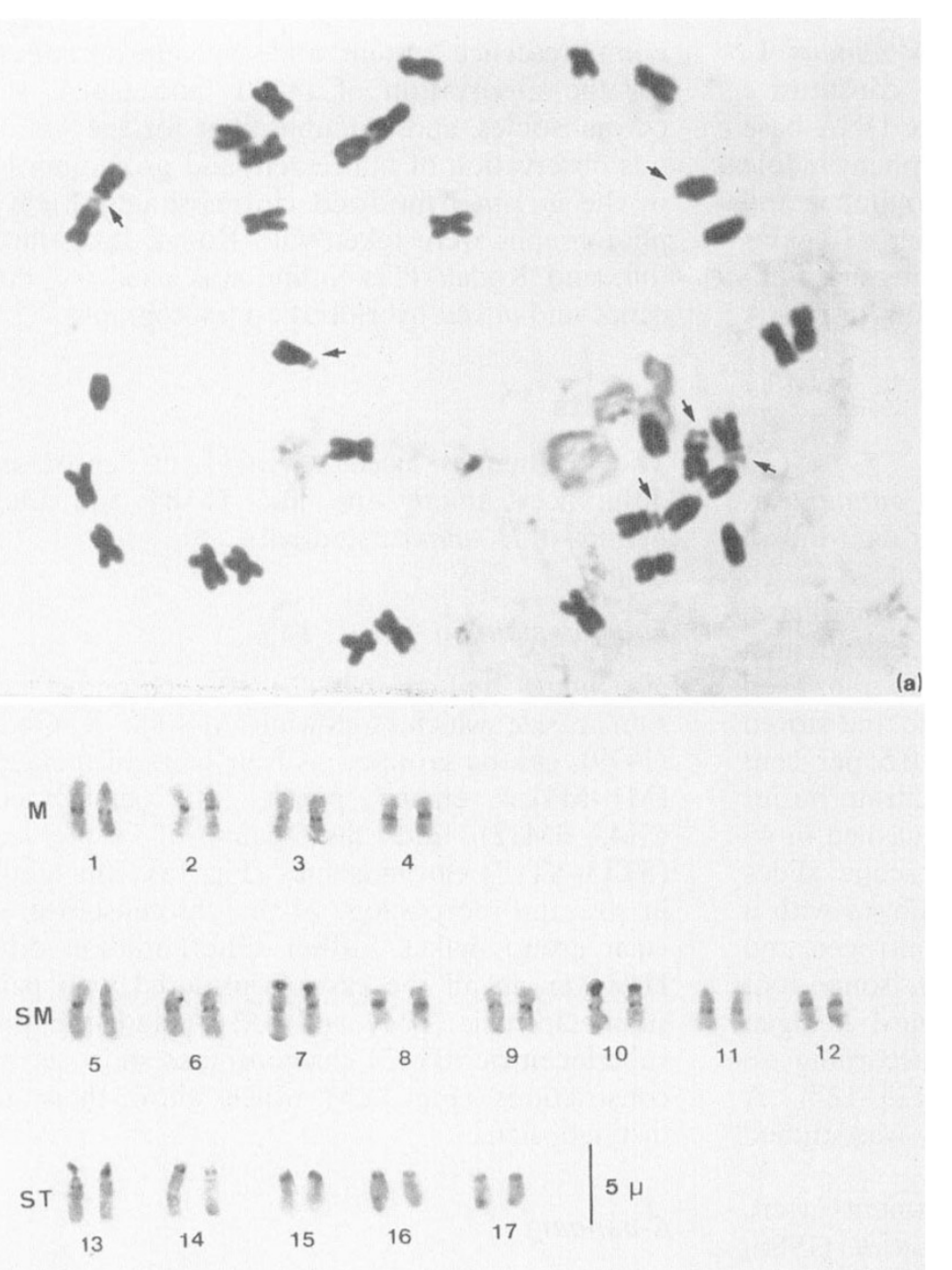

Fig. 1 (a) Feulgen-stained mitotic metaphase chromosomes of the hybrid Flamme of Helianthus annuus. Note the existence of three pairs of chromosomes bearing secondary constrictions (arrows). (b) C-banded karyotype of the inbred line HA89. The heterochromatin is restricted to the centromeric areas and the secondary constrictions of the satellite chromosomes (pairs SM7, SM10 and ST13).
No other differentiation is revealed with this latter treatment (Fig. 2b). None of these fluorescence techniques has differentiated non-C-heterochromatic regions.

\section{Silver staining}

Silver precipitates attached to the secondary constrictions are shown by the three pairs of satellite chromosomes: SM7, SM10 and ST13 (Fig. 3a). Interphase nuclei show between one and six spots of silver. In a sample of 537 silver-stained interphase meristem cells, 39.8 per cent had one nucleolus, 25.6 per cent had two, 28.3 per cent had three, 4.4 per cent four, 1.1 per cent five and 0.5 per cent six nucleoli.

\section{FISH}

The chromosomal in situ hybridization of the rDNA probe confirms the existence of ribosomal clusters associated with the secondary constrictions of the three pairs of chromosomes (Fig. 3b). Hybridization does not occur in any other location and interphase nuclei consistently show six hybridization sites (close to 99 per cent nuclei in a sample of 214 cells).

\section{Discussion}

Despite the economic and evolutionary importance of the genus Helianthus its cytogenetics has hitherto not been investigated in any great detail. This is partially because of the intrinsic difficulty of obtain- 

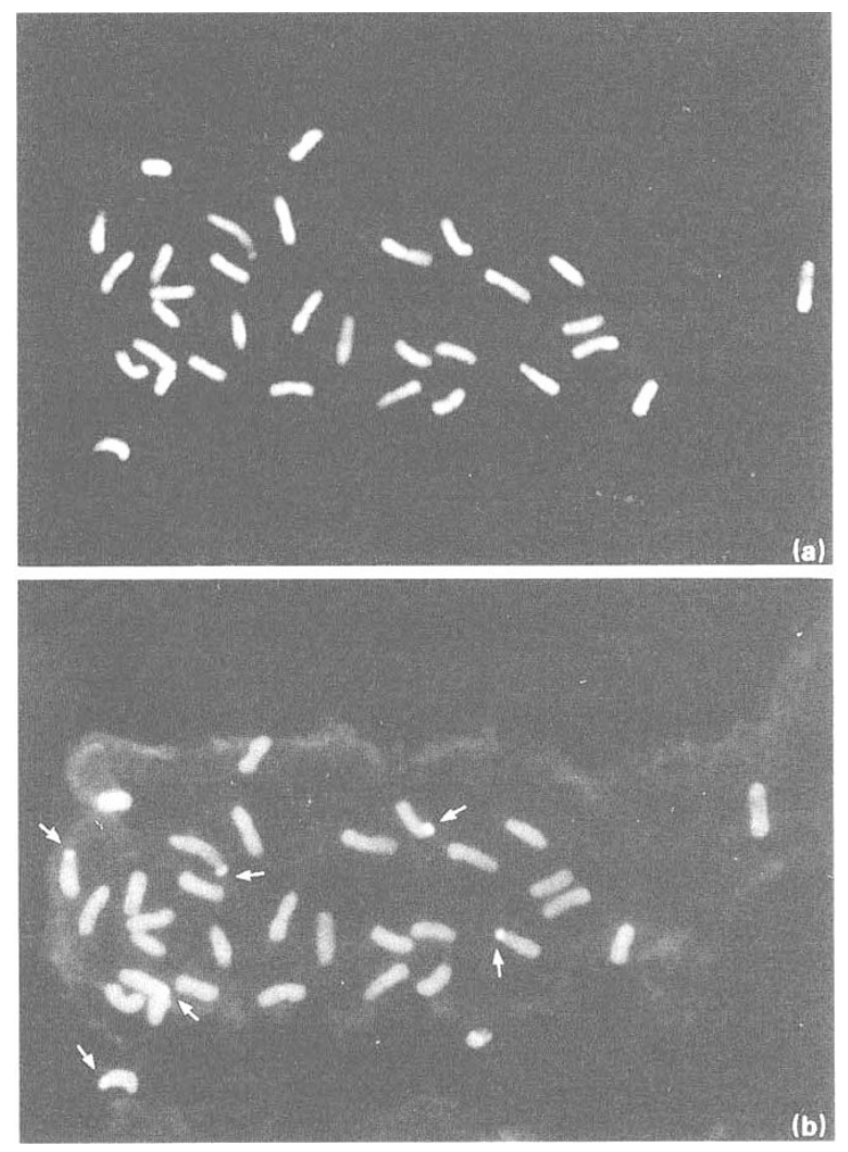

Fig. 2 Fluorescent tri-staining of the mitotic metaphase chromosomes of the commercial hybrid Flamme of Helianthus annuus. The DA-DAPI treatment (a) does not show clear differentiation whereas there is positive response to the DA-CMA3 staining of the heterochromatin associated with the secondary constrictions (b).

ing mitotic chromosome preparations of sufficient quality. The enzymatic pretreatment of the meristematic root tissues with pectinase helps to solve this problem, as is commonly observed in other plants. The chromosome number and karyomorphology of the line and varieties of $H$. annuus var. macrocarpus studied here agree with those described by other authors for other varieties (Al-Allaf \& Godward, 1979; Chandler, 1991). However, there have been no previous studies of heterochromatin distribution, chromosomal response to specific DNA sequence fluorochromes, or rDNA activity and location.

The absence of variation in the C-heterochromatin distribution within and between the inbred line and varieties studied here suggests that this is very probably the standard heterochromatin pattern of the macrocarpus variety, which is the most

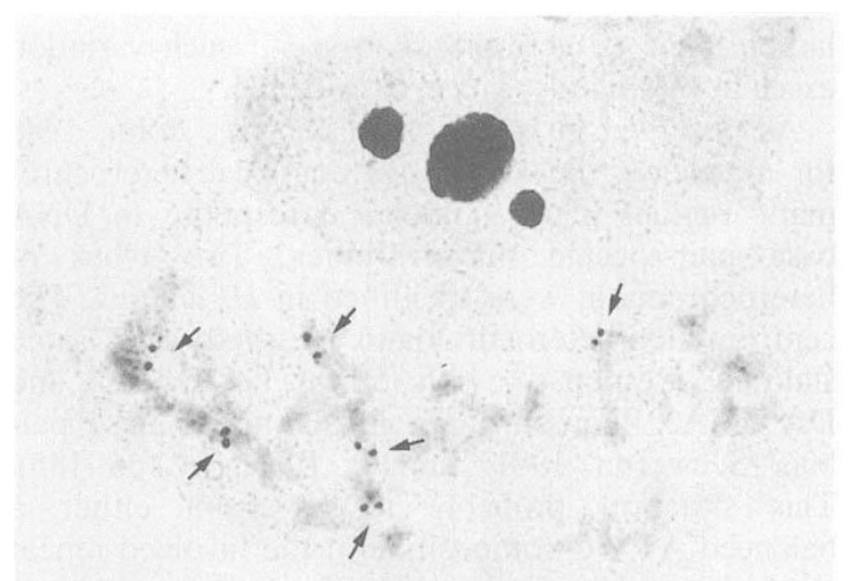

(a)

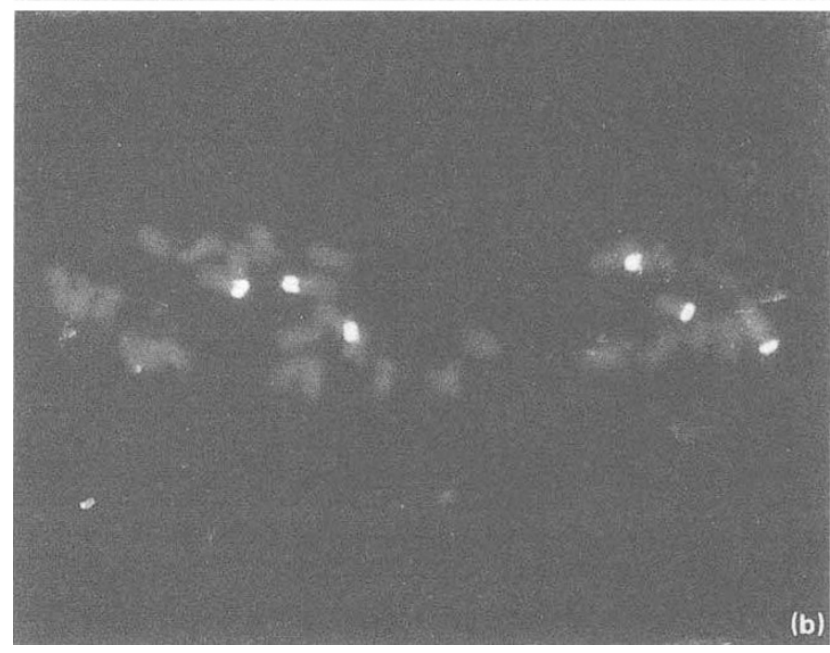

Fig. 3 In the inbred line HA89 of Helianthus annuus the silver staining (a) shows six silver spots (NORs) attached to the secondary constrictions of pairs SM7, SM10 and ST13 (arrows) in the mitotic metaphase chromosomes. These results are confirmed by FISH with an rDNA probe (b). Note also the three nucleoli in the interphase nucleus in (a).

commonly cultivated sunflower. However, this does not imply that this pattern is invariable within $H$. annuus. It is reasonable to expect that in natural populations of $H$. annuus there exist polymorphisms for the distribution, size or even composition of the heterochromatin. The lack of karyological information concerning this genus precludes comparison of the C-band distribution reported here with the banding pattern of other Helianthus species and varieties. C-band variation can provide valuable cytotaxonomic information as has been shown in work on the related Anthemidea (Schweizer \& Ehrendorfer, 1983). It would therefore be useful to survey a 
larger range of germplasm to see if such variation exists in $H$. annuus.

As observed in other organisms (see John, 1988 for a review), the $H$. annuus equilocal heterochromatic regions have an identical response to DNA base pair-specific fluorochromes. Two types of heterochromatin were identified in $H$. annuus. The centromeric heterochromatin showed the same staining response with the DA-DAPI and DA-CMA3 fluorochromes, indicating no base pair bias (Schweizer, 1981; Sumner, 1990, pp. 155-185). This situation probably results from either a balanced AT/GC composition of the involved repeat or the existence of alternating repetitive sequences of opposite base pair composition in these heterochromatic areas. However, the heterochromatin in the secondary constrictions of the satellited chromosomes was DA-CMA3-positive, showing that it was GC-rich. In any case, the two types of heterochromatin revealed by these treatments confirm, at the cytological level, the coexistence of distinct families of DNA repetitive sequences in the genome of $H$. annuus that have also been distinguished by molecular analysis (K. Sossey, personal communication). DNA content within the genus Helianthus exhibits a four-fold range of variation largely because of polyploidy; however, there is also considerable variation in DNA content and chromosome size among sunflower species with the same chromosome number. For example, H. annuus (HA89) has the fourth lowest DNA content of the 19 species with $2 n=34$ chromosomes (Sims \& Price, 1985). Intraspecific variation in DNA content amongst cultivated varieties and inbred lines of $H$. annuus has also been described (Cavallini et al., 1986; Chandler, 1991; Michaelson et al., 1991). To what extent different amounts of heterochromatin may be involved in this DNA content variation remains to be elucidated, but from our results we know that HA89 has little constitutive heterochromatin, which is confined to small bands in the centromeric areas and secondary constrictions. Further molecular and cytological studies will investigate this relationship.

Silver staining reveals active ribosomal genes (Hubbell, 1985). In root meristem cells from HA89 and the two hybrids of $H$. annuus, the three pairs of satellite chromosomes show silver deposits attached to the secondary constrictions, revealing the position of active rDNA clusters. This coincidence with secondary constrictions as well as the GC richness of the associated heterochromatin are common features of NORs (Schweizer, 1980). The in situ hybridization with an rDNA probe confirms the number and location of the rDNA clusters and makes the existence of other inactive ribosomal sites unlikely. The existence of one to three silver spots in most of the interphase nuclei of root meristem cells (93.7 per cent) is probably the result of nucleolar fusion (Giménez-Martín et al., 1977) although FISH with the rDNA probe shows six clearly separated fluorescent dots in the majority of the interphase cells. The six chromosomes with rDNA clusters show silver deposits attached to them at metaphase, indicating that all of them were active during the preceding interphase (Miller et al., 1976).

The search for chromosomal markers in other species of the genus Helianthus is helpful in a taxon where (i) there are diploid, tetraploid and hexaploid species, all of which have a basic chromosome number of $\mathrm{x}=17$ and are probably of polyploid origin (Jackson \& Murray, 1983; Chandler et al., 1986); (ii) different races of the same Helianthus species may be chromosomally distinct, although successful crosses may be produced between perennial and annual species, and between diploid and polyploid species (Kulshreshtha \& Gupta, 1979); (iii) the cytogenetical information comes almost exclusively from the analysis of interspecific hybrid meiotic configurations (Chandler, 1991). These chromosomal markers could be useful either from the taxonomic point of view to identify chromosomes from different genomes or to follow the introgression of alien chromosomes in cultivated sunflowers, as happens in other plant species (Gustafson \& Dille, 1992; Werner et al., 1992). In any case, the existence of linkage maps in the sunflower (Rieseberg et al., 1993; Gentzbittel et al., 1995) where ribosomal gene polymorphisms have been described (Choumane \& Heizmann, 1988) might permit the chromosomes with NORs to be assigned to linkage groups. Current work on sunflower RFLP maps may also yield in situ hybridization probes of use in assigning linkage groups to chromosomes.

The study of the constitutive heterochromatin distribution and fluorochrome response, as well as the number and location of the rDNA sequences in other species and other varieties of Helianthus will provide complementary information on their evolutionary status and, hopefully, suitable markers for breeding studies. Combined research on breeding, cytogenetics and molecular techniques are required in the sunflower to understand natural and artificial interspecific gene transfer (introgression) and the selective forces involved (Belhassen et al., 1994), as well as to provide new tools to evaluate variability in this taxon.

(C) The Genetical Society of Great Britain, Heredity, 76, 586-591. 


\section{Acknowledgements}

We are grateful to Drs J. Gosálvez, P. L. Mason and M. Navarrete for their very valuable help. This work has been partially supported by the Spanish-French programme of 'Acciones Integradas', and grants AGF93-0869 and SAF93-0093 from the Spanish CICYT.

\section{References}

AL-AllaF, s. AND GodWARD, M. B. E. 1979. Karyotype analysis of four varieties of Helianthus annuus L. Cytologia, 44, 319-323.

BELhASSEN, E., AUGE, G., JI, J., BILLOT, C., FERNÁNDEZMARTíneZ, J., RUSO, J. AND VARes, D. 1994. Dynamic management of genetic resources: first generation analysis of sunflower artificial populations. Génét. Sél. Évol., 26, 241-253.

CAVAllini, A., ZOLFINO, C., CIONINI, G., CREMONINI, R., NATALI, L., SASSOLI, O. AND CIONINI, P. G. 1986. Nuclear DNA changes within Helianthus annuus L.: cytophotometric, karyological and biochemical analyses. Theor. Appl. Genet., 73, 20-26.

CHANDLER, J. M. 1991. Chromosome evolution in sunflower. In: Tsuchiya, P. and Gupta, P. K (eds) Chromosome Engineering in Plants: Genetics, Breeding, Evolution, part B, pp. 229-249. Elsevier, Amsterdam.

CHANDleR, J. M., JAN, C. AND BEARD, B. H. 1986. Chromosomal differentiation among the annual Helianthus species. Syst. Bot., 11, 354-371.

CHOUMANE, w. AND HEIZMANN, P. 1988. Structure and variability of nuclear ribosomal genes in the genus Helianthus. Theor. Appl. Genet., 76, 481-489.

DARLINGTON, C. D. AND LA COUR, L. F. 1976. The Handling of Chromosomes, 6th edn. George Allen \& Unwin Ltd, London.

GENTZBITTEL, L., VEAR, F., ZHANG, Y. X., BERVILLE, A. AND NICOLAS, P. 1995. Development of a consensus linkage map of cultivated sunflower (Helianthus annuus L.). Theor. Appl. Genet., 90, 1079-1086.

GERLACH, W. L. AND BEDBROOK, J. R. 1979. Cloning and characterization of ribosomal RNA genes from wheat and barley. Nucl. Acids Res., 7, 1869-1885.

GiMÉNEZ-MARTín, G., DE LA TORRE, C., LóPEZ-SÁEZ, J. F. AND ESPONDA, P. 1977. Plant nucleolus: structure and physiology. Cytobiologie, 14, 421-462.

guSTAFSON, J. P. AND Dille, J. E. 1992. Chromosome location of Oryza sativa recombination linkage groups. Proc. Natl. Acad. Sci. U.S.A., 89, 8646-8650.

HUBBELL, H. R. 1985. Silver staining as an indicator of active ribosomal genes. Stain Technol., 60, 285-294.

JACKSON, R. C. AND MURRAY, B. G. 1983. Colchicine induced quadrivalent formation in Helianthus: evidence for ancient polyploidy. Theor. Appl. Genet., 64, 219-222. JOHN, в. 1988. The biology of heterochromatin. In: Verma, R. S. (ed) Molecular and Structural Aspects of Heterochromatin, pp. 1-147. Cambridge University Press, Cambridge.

KULSHREShTHA, V. B. AND GUPTA, P. K. 1979. Cytogenetic studies in the genus Helianthus L. Cytologia, 44, 325-334.

LACADENA, J. R., CERMEÑo, M. C., ORELLANA, J. AND SANTOS, J. L. 1984. Evidence for wheat-rye nucleolar competition (amphiplasty) in triticale by silver staining procedure. Theor. Appl. Genet., 67, 207-213.

MICHAELSON, M. J., PRICE, H. J., SPENCER-JOHNSTON, J. AND ELLISON, J. R. 1991. Variation of nuclear DNA content in Helianthus annuus (Asteraceae). Am. J. Bot., 78, 1238-1243.

MILleR, D. A., DEV, V. G., TANTRAVAHI, R. AND MILleR, O. J. 1976. Suppression of human nucleolus organizer activity in mouse-human somatic hybrid cells. Exp. Cell Res., 101, 135-243.

PENDÁs, A. M., MORÁN, P. AND GARCÍA-VÁZOUEZ, E. 1993. Ribosomal genes are interspersed throughout a heterochromatic arm in Atlantic salmon. Cytogenet. Cell Genet., 63, 128-130.

RIESEBERG, L. H., CHOI, H., CHAN, R. AND SPORE, C. 1993. Genomic map of a diploid hybrid species. Heredity, 70, 285-293.

SCHILLING, E. E. AND HEISER, C. B., JR. 1981. Infrageneric classification of Helianthus compositae. Taxon, 30, 393-403.

SCHWARZACHER, T., AMBROS, P. AND SCHWEIZER, D. 1980. Application of Giemsa banding to orchid karyotype analysis. Plant Syst. Evol., 134, 293-297.

SCHWEIZER, D. 1976. Reverse fluorescent chromosome banding with Chromomycin and DAPI. Chromosoma, 58, 307-324.

SCHWEIZER, D. 1980. Fluorescent chromosome bands in plants: applications, mechanisms and implications for chromosome structure. In: Davies, D. R. and Hopwood, R. A (eds) The Plant Genome: Proceedings of the 4th John Innes Symposium, pp. 61-72. John Innes Charity, Norwich.

SCHWEIZER, D. 1981. Counterstaining-enhanced chromosome banding. Hum. Genet., 57, 1-14.

SCHWEIZER, D. AND EHRENDORFER, F. 1983. Evolution of C-band patterns in Asteraceae-Anthemideae. Biol. Zbl., 102, 637-655.

SIMS, L. E. AND PRICE, H. J. 1985. Nuclear DNA content variation in Helianthus (Asteraceae). Am. J. Bot., 72, 1213-1219.

Sumner, A. T. 1990. Chromosome Banding. Unwin Hyman Ltd., London.

WERNER, J. E., ENDO, T. R. AND GILL, B. S. 1992. Towards a cytogenetically based physical map of the wheat genome. Proc. Natl. Acad. Sci. U.S.A., 89, 11307-11311. 